\title{
Estimation of Congestion in Free Disposal Hull Models Using Data Envelopment Analysis
}

\author{
M. Abbasi, G. R. Jahanshahloo, M. Rostamy-Malkhlifeh, and F. Hosseinzadeh Lotfi \\ Department of Mathematics, Islamic Azad University, Science and Research Branch, Tehran 1477893855, Iran \\ Correspondence should be addressed to M. Rostamy-Malkhlifeh; mohsen_rostamy@yahoo.com
}

Received 21 May 2014; Revised 14 July 2014; Accepted 20 July 2014; Published 15 October 2014

Academic Editor: Mohammad Khodabakhshi

Copyright ( $) 2014$ M. Abbasi et al. This is an open access article distributed under the Creative Commons Attribution License, which permits unrestricted use, distribution, and reproduction in any medium, provided the original work is properly cited.

\begin{abstract}
This paper deals with evaluating congestion in free disposal hull (FDH) models. There are several approaches in data envelopment analysis (DEA) literatures which discuss the theory and application of congestion. However, almost all of these approaches considered convex DEA technologies. So, in the case of nonconvex technologies, including FDH technology, this field is almost nil. This paper makes an attempt to fill in this void. To do so, this study provides a pairwise comparisons-based algorithm to evaluate congestion in FDH model. This algorithm identifies the sources of congestion and estimates its amounts. It is also capable of detecting the losses amounts of output due to congestion. The validity of the proposed model is demonstrated using some numerical and empirical examples.
\end{abstract}

\section{Introduction}

Evaluation of decision making units (DMUs) is an important task especially from a managerial point of view. DEA is a nonparametric and mathematical programming based approach for evaluating the performance of a set of homogeneous DMUs using multiple inputs to produce multiple outputs. In performance analysis, in particular in DEA, the concept of congestion plays a seminal role in theory and application. Congestion is a special phenomenon in the production process which is defined in economics where outputs are reduced due to excessive amount of inputs or an increase in one or more outputs results in a reduction in one or more inputs. For an actual example of congestion in a coal mine where a large crowd of the miners are working in a narrow underground, the amount of minerals excavated will be reduced [1].

Heretofore, various approaches have been presented in DEA for the treatment of congestion. The concept of congestion was first introduced in the literatures by Färe and Grosskopf [2] in the context of DEA. Subsequently an operationally implementable form was given by Färe et al. [3] and Cooper et al. [4-6]. Afterwards, Tone and Sahoo [7] developed a new slack-based approach to evaluate the scale elasticity in the presence of congestion with a unified framework. Wei and Yan [8] used DEA output additive models and proposed a necessary and sufficient condition for existence of congestion. Jahanshahloo and Khodabakhshi $[9,10]$ provided an approach of input congestion based on the relaxed combinations of inputs. Later on, Khodabakhshi [11] provided a one-model approach of input congestion based on input relaxation model. Also Khodabakhshi [12] proposed a method to detect the input congestion in the stochastic DEA. To see more references about this approach, the readers are referred to $[13,14]$. Jahanshahloo et al. [15] and Khodabakhshi et al. [16] proposed some methods for computing the congestion in DEA models with production trade-offs and weight restrictions. Sueyoshi and Sekitani [17] proposed a modified approach which is able to measure congestion under the occurrence of multiple solution. There exist some papers which reviewed congestion papers, as that of Khodabakhshi et al. [18].

All of the above-mentioned investigations deal with congestion in convex technologies. In convex models, the targets resulting from efficiency assessment correspond to the points on the continuous efficiency frontiers. This means that DMUs might be compared with unreal DMUs which sometimes is meaningless in real life, for example, when we want to evaluate the efficiency of various car engines. 
FDH models were first formulated by Deprins et al. [19]. The PPS of FDH model is made by deterministic (or observed activities) and free disposability postulates. So the PPS of FDH model is nonconvex. One appealing characteristic of $\mathrm{FDH}$ model due to nonconvexity nature of FDH efficiency frontier is that, in FDH model, targets correspond to observed units which is more compatible with real life because, in some circumstances, the observed unit is more comfortable when compared with a real unit rather than with a virtual one. As can be seen from the foregoing, there are several methods for evaluating congestion in convex DEA models, but for FDH models, although there are a few papers which are concerned with the field of estimation returns to scale (RTS), see, for example, [20-24], methods to estimate congestion can be hardly found. Therefore a new scheme is required to deal with congestion in FDH models.

In this paper, we first present definitions of output efficiency for DMUs under a series of DEA output additive models. Then, using these definitions, we develop a necessary and sufficient condition for existence of congestion in FDH model. Afterwards, we provide a polynomial time algorithm based on pairwise comparisons which evaluates congestion for DMUs using certain differences of inputs and outputs. This algorithm simply identifies the sources of congestion and estimates its amounts for congested DMUs.

The rest of the paper unfolds as follows. In the next section, FDH model and some of its properties and definitions will be presented to facilitate later discussions. In Section 3, we present a method with many computational advantages for evaluating congestion in FDH model. The validity of the proposed model is demonstrated using three numerical examples in Section 4. Finally, Section 5 gives the conclusion of this paper.

\section{Preliminaries}

In this section we first briefly describe some characteristic property of FDH model. Consider $n$ DMUs where each $\mathrm{DMU}_{j}(j=1, \ldots, n)$ utilizes $m$ inputs $x_{i j}(i=1, \ldots, m)$ to produce $s$ outputs $y_{r j}(r=1, \ldots, s)$. Let $x_{j}=\left(x_{1 j}, \ldots, x_{m j}\right)^{T}$ and $y_{j}=\left(y_{1 j}, \ldots, y_{s j}\right)^{T}$. We will also assume that $x_{j} \geq$ $0, x_{j} \neq 0$ and $y_{j} \geq 0, y_{j} \neq 0$. The production possibility set $T$ is represented as

$$
T=\left\{(x, y) \in R_{+}^{m+s} \mid y \text { can be produced from } x\right\}
$$

Deprins et al. [19] have deduced the following production possibility set. This set is denoted by $T_{\mathrm{FDH}}$, regarding the assumptions of deterministic and free disposability of the production technology:

$$
\begin{aligned}
T_{\mathrm{FDH}}= & \left\{(x, y): \sum_{j=1}^{n} \lambda_{j} x_{j} \leq x, \sum_{j=1}^{n} \lambda_{j} y_{j} \geq y,\right. \\
& \left.\sum_{j=1}^{n} \lambda_{j}=1, \lambda_{j} \in\{0,1\}, j=1, \ldots, n\right\} .
\end{aligned}
$$

The additive FDH model to evaluate the efficiency of a special $\mathrm{DMU}_{p}(p \in\{1, \ldots, n\})$ under the $T_{\mathrm{FDH}}$ is as follows:

$$
\begin{array}{ll}
\operatorname{Max} & \sum_{i=1}^{m} s_{i}^{-}+\sum_{r=1}^{s} s_{r}^{+}, \\
\text {s.t. } \quad & \sum_{j=1}^{n} \lambda_{j} x_{i j}+s_{i}^{-}=x_{i p} \quad i=1, \ldots, m, \\
& \sum_{j=1}^{n} \lambda_{j} y_{r j}-s_{r}^{+}=y_{r p} \quad r=1, \ldots, s, \\
& \sum_{j=1}^{n} \lambda_{j}=1, \quad \lambda_{j} \in\{0,1\}, j=1, \ldots, n, \\
& s_{i}^{+} \geq 0 \quad i=1, \ldots, m, \\
& s_{r}^{+} \geq 0 \quad r=1, \ldots, s .
\end{array}
$$

Definition 1 (FDH efficiency). Consider model (3). If the optimal objective value is zero, then $\mathrm{DMU}_{p}$ is said to be FDH efficient.

It is worth noting that different to CCR and BCC models, the FDH model does not operate with the convexity assumption. Therefore, this model has a discrete nature which causes the efficient target point for an inefficient DMU simply to be assigned as a point among only actually observed DMUs. Thus, the efficiency analysis is done relative to the other given DMUs instead of a hypothetical efficiency frontier. This has the advantage that the achievement goal for an inefficient DMU given by its efficient target point will be more credible than in cases of CCR and BCC models.

Definition 2 (FDH output efficiency). Consider the following model. If $Z_{\mathrm{FDH}}=0$, then $\mathrm{DMU}_{p}$ is said to be FDH output efficient:

$$
\begin{aligned}
Z_{\mathrm{FDH}}=\operatorname{Max} & \sum_{r=1}^{s} s_{r}^{+} \\
\text {s.t. } \quad & \sum_{j=1}^{n} \lambda_{j} x_{i j} \leq x_{i p} \quad i=1, \ldots, m \\
& \sum_{j=1}^{n} \lambda_{j} y_{r j}-s_{r}^{+}=y_{r p} \quad r=1, \ldots, s \\
& \sum_{j=1}^{n} \lambda_{j}=1, \quad \lambda_{j} \in\{0,1\}, j=1, \ldots, n, \\
& s_{r}^{+} \geq 0 \quad r=1, \ldots, s .
\end{aligned}
$$

Definition 3 (congestion). Evidence of congestion is present in the performance of any DMU, when a decrease in one or more inputs is associated with increases that are maximally possible in one or more outputs without worsening other inputs or outputs. Conversely, congestion is said to occur when some of the outputs that are maximally possible are 


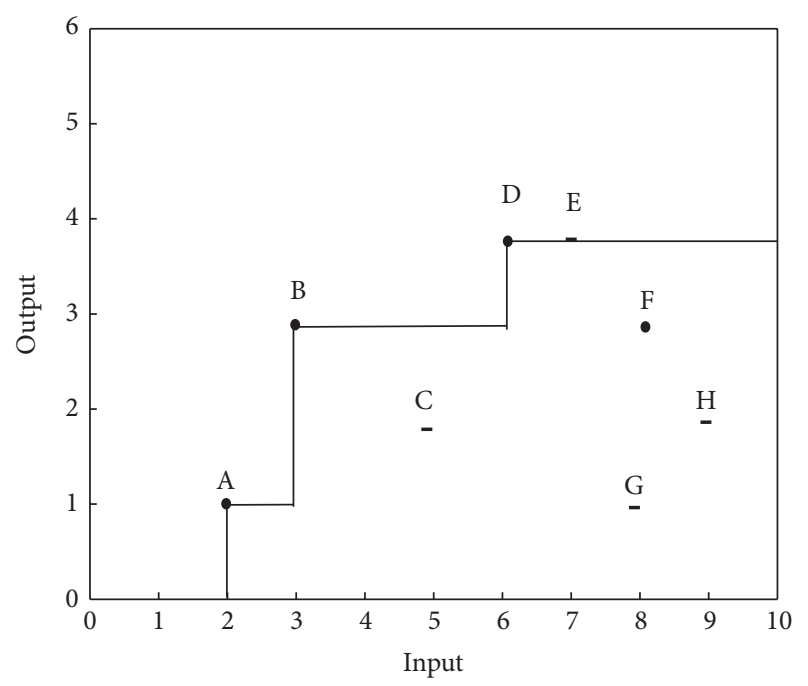

FIGURE 1: $T_{\mathrm{FDH}}$.

reduced by increasing one or more inputs without improving any other inputs or outputs [25].

A very restrictive form of the above definition yields the definition of strong congestion as follows.

Definition 4 (strong congestion). If a proportionate reduction in all inputs of a DMU warrants an increase in all maximally possible outputs, then strong congestion occurs [7].

Definition 5 (technical efficiency). Efficiency is achieved by $\mathrm{DMU}_{0}$ if and only if it is not possible to improve some of its inputs or outputs without worsening some of its other inputs or outputs [25].

Definition 6 (technical inefficiency). Technical inefficiency is said to be present in the performance of $\mathrm{DMU}_{0}$ when the evidence shows that it is possible to improve some input or output without worsening some other inputs or outputs [25].

\section{Congestion in FDH Model}

In $T_{\mathrm{FDH}}$, the efficiency surface is a staircase based on those given DMUs that are not dominated by other given DMUs. Figure 1 describes an illustrative example of $T_{\mathrm{FDH}}$ which is made by eight DMUs denoted by $A, B, \ldots, H$ with one input and one output.

It should be noted that evaluating congestion in customary models for convex PPS has been studied on $T_{\mathrm{NEW}}$, which is a PPS without input disposability postulate. Let us denote $T_{\mathrm{NEW}}$ corresponding to $T_{\mathrm{FDH}}$ as $T_{\mathrm{NFDH}}$, which can be defined as follows:

$$
\begin{aligned}
T_{\mathrm{NFDH}}= & \left\{(x, y) \mid x=\sum_{j=1}^{n} \lambda_{j} x_{j}, y \leq \sum_{j=1}^{n} \lambda_{j} y_{j},\right. \\
& \left.\sum_{j=1}^{n} \lambda_{j}=1, \lambda_{j} \in\{0,1\}, j=1, \ldots, n\right\} .
\end{aligned}
$$

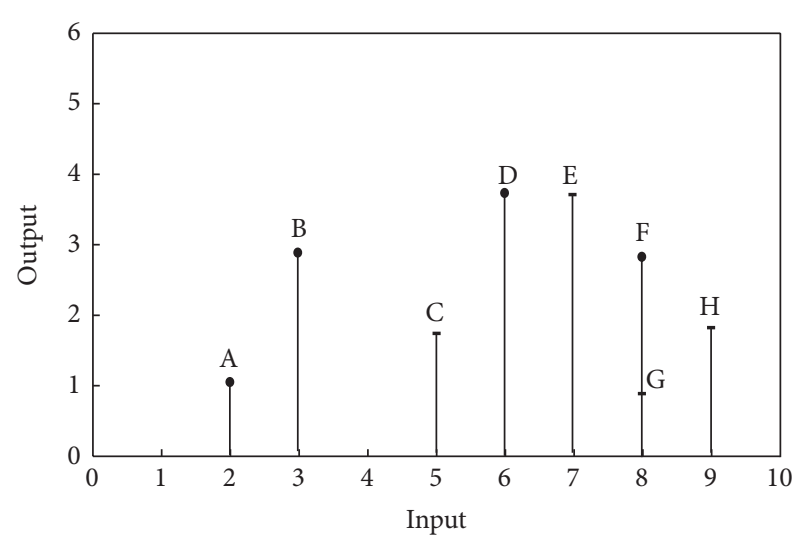

FIGURE 2: $T_{\mathrm{NFDH}}$.

Figure 2 exhibits $T_{\mathrm{NFDH}}$ for the example in Figure 1. As seen from Figure 2, $T_{\mathrm{NFDH}}$ has a discrete nature and so the study of congestion on it is complicated. So to overcome this difficulty we introduce a new set as follows:

$$
\begin{aligned}
\mathrm{FDH}^{-1}= & \left\{(x, y) \mid x \leq \sum_{j=1}^{n} \lambda_{j} x_{j}, y \leq \sum_{j=1}^{n} \lambda_{j} y_{j},\right. \\
& \left.\sum_{j=1}^{n} \lambda_{j}=1, \lambda_{j} \in\{0,1\}, j=1, \ldots, n\right\} .
\end{aligned}
$$

Apparently, the set of $\mathrm{FDH}^{-1}$ is gained by reversing the sign of input inequalities in $T_{\mathrm{FDH}}$. $\mathrm{FDH}^{-1}$ set corresponding to the example in Figure 1 is illustrated in Figure 3.

We use the following model to deal with the congestion phenomenon in FDH model:

$$
\begin{aligned}
Z_{\mathrm{FDH}^{-1}}=\operatorname{Max} & \sum_{r=1}^{s} s_{r}^{+} \\
\text {s.t. } \quad & \sum_{j=1}^{n} \lambda_{j} x_{i j} \geq x_{i p} \quad i=1, \ldots, m \\
& \sum_{j=1}^{n} \lambda_{j} y_{r j}-s_{r}^{+}=y_{r p} \quad r=1, \ldots, s \\
& \sum_{j=1}^{n} \lambda_{j}=1, \quad \lambda_{j} \in\{0,1\}, j=1, \ldots, n \\
& s_{r}^{+} \geq 0 \quad r=1, \ldots, s .
\end{aligned}
$$

We call the above model "FDH ${ }^{-1}$ output additive model."

To see what is involved, we note that the input (like the output) constraints take the form $\sum_{j=1}^{n} \lambda_{j} x_{i j} \geq x_{i p}$. Hence, in this adaptation of additive models, the objective is to maximize the outputs without reducing any of the inputs.

Definition $7\left(\mathrm{FDH}^{-1}\right.$ output efficiency). Consider the model (7). If $Z_{\mathrm{FDH}^{-1}}=0$, then $\mathrm{DMU}_{p}$ is said to be $\mathrm{FDH}^{-1}$ output efficient. 


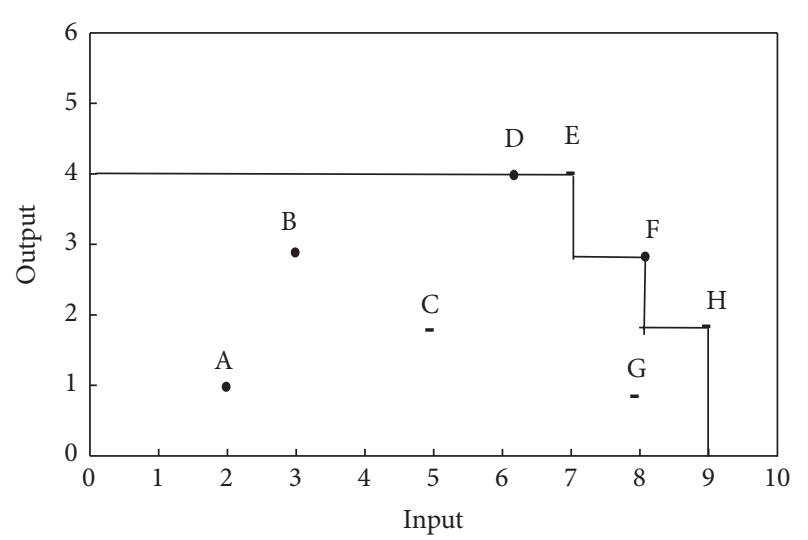

FIGURE 3: $\mathrm{FDH}^{-1}$.

Lemma 8. $D M U_{p}$ is $F D H^{-1}$ output efficient if and only if the following system has no solution:

$$
\begin{gathered}
\sum_{j=1}^{n} \lambda_{j} x_{j} \geq x_{p}, \\
\sum_{j=1}^{n} \lambda_{j} y_{j} \geq y_{p}, \quad \sum_{j=1}^{n} \lambda_{j} y_{j} \neq y_{p}, \\
\sum_{j=1}^{n} \lambda_{j}=1, \quad \lambda_{j} \in\{0,1\}, j=1, \ldots, n .
\end{gathered}
$$

Proof. It is clear using Definition 7.

Definition 9 (congestion in FDH model). Let $\mathrm{DMU}_{p}=$ $\left(x_{p}, y_{p}\right)$ be $\mathrm{FDH}^{-1}$ output efficient; if there exists $\mathrm{DMU}_{k}=$ $\left(x_{k}, y_{k}\right)$, such that $x_{k} \leq x_{p}, x_{k} \neq x_{p}$ and $y_{k} \geq y_{p}, y_{k} \neq y_{p}$, then $\mathrm{DMU}_{p}$ has evidence of congestion.

Based upon Definition 9, units F, G, and H in Figure 3 have evidence of congestion and unit $C$ is technically inefficient.

Definition 10 (strong congestion in FDH model). Let $\mathrm{DMU}_{p}=\left(x_{p}, y_{p}\right)$ be congested in FDH model; if there exists $\mathrm{DMU}_{k}=\left(x_{k}, y_{k}\right)$, such that $x_{k}<x_{p}$ and $y_{k}>y_{p}$, then $\mathrm{DMU}_{p}$ has evidence of strong congestion.

Lemma 11. Let $D M U_{p}$ be $F D H^{-1}$ output efficient; then $D M U_{p}$ has evidence of congestion if and only if the following system has a solution:

$$
\begin{gathered}
\sum_{j=1}^{n} \lambda_{j} x_{j} \leq x_{p}, \\
\sum_{j=1}^{n} \lambda_{j} y_{j} \geq y_{p}, \quad \sum_{j=1}^{n} \lambda_{j} y_{j} \neq y_{p}, \\
\sum_{j=1}^{n} \lambda_{j}=1, \quad \lambda_{j} \in\{0,1\}, \quad j=1, \ldots, n .
\end{gathered}
$$

Proof. Let $\mathrm{DMU}_{p}$ has evidence of congestion, so from Definition 9, there exists $\mathrm{DMU}_{k}=\left(x_{k}, y_{k}\right)$, such that $x_{k} \leq$ $x_{p}, x_{k} \neq x_{p}$ and $y_{k} \geq y_{p}, y_{k} \neq y_{p}$. Thus $\lambda_{k}=1$ and $\lambda_{j}=0(j=1, \ldots, n, j \neq k)$ is a solution of (9).

Conversely, suppose that $\widetilde{\lambda}=(0, \ldots, 0,1,0, \ldots, 0)$, whose qth component is one, is a solution of (9). So, we have $x_{q} \leq x_{p}$ and $y_{q} \geq y_{p}, y_{q} \neq y_{p}$. Also, certainly $x_{q} \neq x_{p}$, since, according to the assumption of lemma, $\mathrm{DMU}_{p}$ is $\mathrm{FDH}^{-1}$ output efficient, so $x_{q}=x_{p}$ contradicts Lemma 8 . Hence, by Definition 9, $\mathrm{DMU}_{p}$ has evidence of congestion.

Lemma 12. $D M U_{p}$ is not FDH output efficient if and only if the following linear system has a solution:

$$
\begin{gathered}
\sum_{j=1}^{n} \lambda_{j} x_{j} \leq x_{p}, \\
\sum_{j=1}^{n} \lambda_{j} y_{j} \geq y_{p}, \quad \sum_{j=1}^{n} \lambda_{j} y_{j} \neq y_{p}, \\
\sum_{j=1}^{n} \lambda_{j}=1, \quad \lambda_{j} \in\{0,1\}, j=1, \ldots, n .
\end{gathered}
$$

Proof. Using definition of FDH output efficiency, the proof is completed.

We now present the main result of the proposed method.

Theorem 13. Let $D M U_{p}$ be $F D H^{-1}$ output efficient; then $D M U_{p}$ has evidence of congestion if and only if $D M U_{p}$ is not FDH output efficient.

Proof. Using Lemmas 11 and 12, the proof is completed.

Now, using Theorem 13, we can provide the following procedure to evaluate congestion in FDH model.

(1) Solve model (7) corresponding to $\left(x_{p}, y_{p}\right)$; let $\left(\lambda^{*}, s^{+*}\right)$ be the optimal solution of it. Let $\hat{y}_{p}=y_{p}+s^{+*}$. It is evident that $\left(x_{p}, \hat{y}_{p}\right)$ is $\mathrm{FDH}^{-1}$ output efficient.

(2) Solve model (4) for $\left(x_{p}, \widehat{y}_{p}\right)$.

(3) If $Z_{\mathrm{FDH}}>0$, then $\mathrm{DMU}_{p}$ is congested.

Remark 14. Models (4) and (7) are mixed-integer programming, but we can simply show that it does not need any mathematical programming problem to solve. Indeed, an enumeration algorithm based on pairwise comparisons, similar to Tulken's enumeration algorithm for the case of radial FDH model [26], can be used.

Now, based upon foregoing procedure and Remark 14, we propose the following algorithm. The proposed algorithm includes two parts. In Part (a), we recognize the existence of congesting in performance of $\mathrm{DMU}_{p}$ and in Part (b), if $\mathrm{DMU}_{p}$ is recognized to be congested in Part (a), the amount 
TABLE 1: Data set and results of Part (a) of the proposed algorithm in Example 1.

\begin{tabular}{lllccccccc}
\hline DMUs & $I$ & $O$ & $D_{p}$ & $Z_{\mathrm{FDH}^{-1}}$ & $s^{+*}$ & $\widehat{y}_{p}$ & $\widehat{D}_{p}$ & $Z_{\mathrm{FDH}}$ & \multicolumn{1}{c}{ Status } \\
\hline $\mathrm{A}$ & 2 & 1 & $\{\mathrm{~A}, \mathrm{~B}, \mathrm{C}, \mathrm{D}, \mathrm{E}, \mathrm{F}\}$ & 3 & 3 & 4 & $\{\mathrm{~A}\}$ & No congestion \\
$\mathrm{B}$ & 3 & 3 & $\{\mathrm{~B}, \mathrm{D}, \mathrm{E}, \mathrm{F}\}$ & 1 & 1 & 4 & $\{\mathrm{~B}\}$ & 0 & No congestion \\
$\mathrm{C}$ & 5 & 2 & $\{\mathrm{C}, \mathrm{E}, \mathrm{F}, \mathrm{H}\}$ & 2 & 2 & 4 & \{\} & No congestion \\
$\mathrm{D}$ & 6 & 4 & $\{\mathrm{D}, \mathrm{E}\}$ & 0 & 0 & 4 & $\{\mathrm{D}\}$ & 0 & No congestion \\
$\mathrm{E}$ & 7 & 4 & $\{\mathrm{E}\}$ & 0 & 0 & 4 & $\{\mathrm{D}\}$ & 0 & No congestion \\
$\mathrm{F}$ & 8 & 3 & $\{\mathrm{~F}\}$ & 0 & 0 & 3 & $\{\mathrm{~B}, \mathrm{D}, \mathrm{E}\}$ & 1 & Congestion \\
$\mathrm{G}$ & 8 & 1 & $\{\mathrm{~F}, \mathrm{G}, \mathrm{H}\}$ & 2 & 2 & 3 & $\{\mathrm{~B}, \mathrm{D}, \mathrm{E}, \mathrm{F}\}$ & 1 & Congestion \\
$\mathrm{H}$ & 9 & 2 & $\{\mathrm{H}\}$ & 0 & 0 & 2 & $\{\mathrm{~B}, \mathrm{C}, \mathrm{D}, \mathrm{E}, \mathrm{F}\}$ & 2 & Congestion \\
\hline
\end{tabular}

of congestion for each input as well as the reduction amount of each output due to congestion will be estimated.

\section{Proposed Algorithm}

Part (a)

Step 1. Calculate the optimal value of model (7) by the following equation:

$$
Z_{\mathrm{FDH}^{-1}}=\sum_{r=1}^{s}\left(y_{r q}-y_{r p}\right)=\max _{j \in D_{p}} \sum_{r=1}^{s}\left(y_{r j}-y_{r p}\right),
$$

where

$$
D_{p}=\left\{j \in\{1, \ldots, n\} \mid x_{j} \geq x_{p} \text { and } y_{j} \geq y_{p}\right\} .
$$

Step 2. Let $\hat{y}_{p}=y_{p}+s^{+*}$, where $s^{+*}=y_{q}-y_{p}$. Obtain the optimal value of model (4) by

$$
Z_{\mathrm{FDH}}=\max _{j \in \widehat{D}_{p}} \sum_{r=1}^{s}\left(y_{r j}-\widehat{y}_{r p}\right),
$$

where

$$
\widehat{D}_{p}=\left\{j \in\{1, \ldots, n\} \mid x_{j} \leq x_{p} \text { and } y_{j} \geq \widehat{y}_{p}\right\} \text {. }
$$

Step 3. If $Z_{\mathrm{FDH}}>0$, then $\mathrm{DMU}_{p}$ is congested, so go to Part (b); furthermore, if there exist $j \in \widehat{D}_{p}$ such that $x_{j}<x_{p}$ and $y_{j}>\widehat{y}_{p}$, then, based on Definition $4, \mathrm{DMU}_{p}$ is strongly congested. If $Z_{\mathrm{FDH}}=0$, then $\mathrm{DMU}_{p}$ is not congested and stop.

Part (b)

Step 4. Define $K_{p}$ as follows:

$$
K_{p}=\left\{j \in \widehat{D}_{p} \mid Z_{\mathrm{FDH}}=\sum_{r=1}^{s}\left(y_{r j}-\widehat{y}_{r p}\right)\right\} .
$$

Then calculate

$$
\alpha^{*}=\min _{j \in k_{p}} \sum_{i=1}^{m}\left(x_{i p}-x_{i j}\right)
$$

TABLE 2: Results of Part (b) of the proposed algorithm in Example 1.

\begin{tabular}{lccccc}
\hline DMUs & $k_{p}$ & $\alpha^{*}$ & $T_{p}$ & $s^{c *}$ & $\widehat{s}^{+*}$ \\
\hline $\mathrm{F}$ & $\{\mathrm{E}, \mathrm{D}\}$ & 1 & $\{\mathrm{E}\}$ & 1 & 1 \\
$\mathrm{G}$ & $\{\mathrm{E}, \mathrm{D}\}$ & 1 & $\{\mathrm{E}\}$ & 1 & 1 \\
$\mathrm{H}$ & $\{\mathrm{E}, \mathrm{D}\}$ & 2 & $\{\mathrm{E}\}$ & 2 & 2 \\
\hline
\end{tabular}

Step 5. Define $T_{p}$ as follows:

$$
T_{p}=\left\{j \in K_{p} \mid \alpha^{*}=\sum_{i=1}^{m}\left(x_{i p}-x_{i j}\right)\right\} .
$$

For $j \in T_{p}$ define $s_{i}^{c *}$ as the amount of congestion in $i$ th input of $\mathrm{DMU}_{p}$ and $\widehat{s}_{r}^{+*}$ as reduction amount of $r$ th output due to congestion as follows:

$$
\begin{aligned}
& s_{i}^{c *}=x_{i p}-x_{i j}, \quad i=1, \ldots, m, \\
& \hat{s}_{r}^{+*}=y_{r j}-\widehat{y}_{r p}, \quad r=1, \ldots, s .
\end{aligned}
$$

$\alpha^{*}=\sum_{i=1}^{m} s_{i}^{c *}$ is the total amount of congestion in all inputs of $\mathrm{DMU}_{p}$.

Corollary 15. If $\widehat{D}_{p}=\emptyset$, congestion has no appearance at $D M U_{p}$.

Proof. In this case, it is obvious that system (10) has no solution. So, by Lemma $12,\left(x_{p}, \hat{y}_{p}\right)$ is FDH output efficient and regarding Theorem 13 congestion has no appearance at $\left(x_{p}, \widehat{y}_{p}\right)$. Since congestion is a frontier concept, then $\mathrm{DMU}_{p}$ has no congestion

Remark 16. If $\operatorname{Card}\left(\left\{j \in D_{p} \mid Z_{\mathrm{FDH}^{-1}}=\sum_{r=1}^{s}\left(y_{r j}-y_{r p}\right)\right\}\right)>$ 1 , then the projection of $\mathrm{DMU}_{p},\left(x_{p}, \hat{y}_{p}\right)$, is not determined uniquely.

Remark 17. $\operatorname{Card}\left(T_{p}\right) \geq 1$. If $\operatorname{Card}\left(T_{p}\right)=1$, then the amount of congestion can be uniquely determined; otherwise there are alternatives for the amount of congestion for $\mathrm{DMU}_{p}$.

Using the above algorithm, we can evaluate the congestion for each DMU in FDH model without any mathematical programming problems and with only some certain pairwise differences of inputs and outputs with regard to (11), (16), and (18). Therefore, the following theorem is obviously true. 
TABLE 3: Data set and results of Part (a) of the proposed algorithm in Example 2.

\begin{tabular}{lcccccccrr}
\hline DMUs & $\left(I_{1}, I_{2}\right)$ & $\left(\mathrm{O}_{1}, \mathrm{O}_{2}\right)$ & $D_{p}$ & $Z_{\mathrm{FDH}^{-1}}$ & $\left(s_{1}^{+*}, s_{2}^{+*}\right)$ & $\widehat{y}_{p}$ & $\widehat{D}_{p}$ & $Z_{\mathrm{FDH}}$ & Status \\
\hline A & $(1,1)$ & $(1,1)$ & $\mathrm{A}, \mathrm{B}, \mathrm{C}, \mathrm{D}$ & 2 & $(1,1)$ & $(2,2)$ & \{\} & No congestion \\
$\mathrm{B}$ & $(2,2)$ & $(2,2)$ & $\mathrm{B}$ & 0 & $(0,0)$ & $(2,2)$ & $\{\mathrm{B}\}$ & 0 & No congestion \\
$\mathrm{C}$ & $(2,3)$ & $(2,1)$ & $\mathrm{C}$ & 0 & $(0,0)$ & $(2,1)$ & $\{\mathrm{B}, \mathrm{C}\}$ & 1 & Congestion \\
$\mathrm{D}$ & $(3,3)$ & $(1,1)$ & $\mathrm{D}$ & 0 & $(0,0)$ & $(1,1)$ & $\{\mathrm{A}, \mathrm{B}, \mathrm{C}, \mathrm{D}\}$ & 2 & Congestion \\
\hline
\end{tabular}

TABLE 4: Result of Part (b) of the proposed algorithm in Example 2.

\begin{tabular}{lccccc}
\hline DMUs & $K_{p}$ & $\alpha^{*}$ & $T_{p}$ & $\left(s_{1}^{c *}, s_{2}^{c^{*}}\right)$ & $\left(\widehat{s}_{1}^{+*}, \widehat{s}_{2}^{+*}\right)$ \\
\hline $\mathrm{C}$ & $\{\mathrm{B}\}$ & 1 & $\{\mathrm{~B}\}$ & $(0,1)$ & $(0,1)$ \\
$\mathrm{D}$ & $\{\mathrm{B}\}$ & 2 & $\{\mathrm{~B}\}$ & $(1,1)$ & $(1,1)$ \\
\hline
\end{tabular}

Theorem 18. The proposal algorithm is a polynomial time algorithm.

\section{Numerical Examples}

In this section, we apply our proposed procedure to measure the congestion effect on two numerical examples and an empirical example.

Example 1. We consider the illustrative example provided in Section 3 which includes eight DMUs, A, B, C, D, E, F, G, and $\mathrm{H}$, with one output and one input each, as shown in Figure 1. The data set of DMUs as well as the results of Part (a) of the proposed algorithm is given in Tables 1 and 2 displays results of Part (b). As shown in Table 1, there is no congestion in DMUs $\mathrm{A}, \mathrm{B}, \mathrm{C}, \mathrm{D}$, and $\mathrm{E}$ and congestion has appeared in DMUs F, G, and $\mathrm{H}$. The input congestion amount and reduction amount of output due to congestion for congested units, resulting from the proposed algorithm, have been provided in the two last columns of Table 2 , respectively. Obviously, in the case of one input and one output, each congested unit has evidence of strong congestion.

Example 2. We consider an example adopted from Tone and Sahoo ([7], page 756) which has been listed in Table 3 of our study. This example consists of four DMUs, A, B, C, and D, using two inputs and producing two outputs. The results of Part (a) of the proposed algorithm are given in Table 3. From Table 3 we can see that there is no congestion in DMUs A and B. As shown in Table 4, for unit $\mathrm{C}$, the congestion amount of inputs is $\left(s_{1}^{c *}, s_{2}^{c *}\right)=(0,1)$ and $\left(\widehat{s}_{1}^{+*}, \widehat{s}_{2}^{+*}\right)=(0,1)$ is output losses of $\mathrm{C}$ due to congestion. For unit $\mathrm{D}$, the congestion amount of inputs is $\left(s_{1}^{c *}, s_{2}^{c *}\right)=(1,1)$ and $\left(\widehat{s}_{1}^{+*}, \widehat{s}_{2}^{+*}\right)=(1,1)$ is output losses of $\mathrm{D}$ due to congestion. Therefore considering Definition 10, unit D is strongly congested.

Example 3. Table 5 presents the input and output data of the Chinese textile industry during 1981-1997 assembled by Cooper et al. [5]. Each year has been treated as a DMU with two inputs and one output: labor $\left(X_{1}\right)$ measured in units of 1000 persons, capital $\left(X_{2}\right)$ measured in units of one million Ren Min Be (Chinese monetary unit), and output
TABle 5: Data set in Example 3.

\begin{tabular}{lccc}
\hline DMU $=$ year & Labor $\left(X_{1}\right)$ & Capital $\left(X_{2}\right)$ & Output $(Y)$ \\
\hline DMU $_{1}=1981$ & 389.00 & 19.86 & 856.02 \\
$\mathrm{DMU}_{2}=1982$ & 412.30 & 21.16 & 866.85 \\
$\mathrm{DMU}_{3}=1983$ & 423.50 & 17.08 & 956.04 \\
$\mathrm{DMU}_{4}=1984$ & 417.30 & 18.10 & 1082.94 \\
$\mathrm{DMU}_{5}=1985$ & 570 & 12.61 & 1273.20 \\
$\mathrm{DMU}_{6}=1986$ & 600.50 & 13.45 & 1230.72 \\
$\mathrm{DMU}_{7}=1987$ & 641.10 & 15.91 & 1410.66 \\
$\mathrm{DMU}_{8}=1988$ & 715.30 & 23.72 & 1728.16 \\
$\mathrm{DMU}_{9}=1989$ & 736.00 & 25.97 & 2109.57 \\
$\mathrm{DMU}_{10}=1990$ & 745.00 & 18.24 & 2291.08 \\
$\mathrm{DMU}_{11}=1991$ & 756.00 & 14.40 & 2533.27 \\
$\mathrm{DMU}_{12}=1992$ & 743.00 & 17.50 & 2899.16 \\
$\mathrm{DMU}_{13}=1993$ & 684.00 & 25.08 & 3520.74 \\
$\mathrm{DMU}_{14}=1994$ & 691.00 & 25.45 & 4949.93 \\
$\mathrm{DMU}_{15}=1995$ & 673.00 & 29.35 & 4604.00 \\
$\mathrm{DMU}_{16}=1996$ & 634.00 & 23.05 & 4722.29 \\
$\mathrm{DMU}_{17}=1997$ & 596.00 & 25.02 & 4760.28 \\
\hline
\end{tabular}

$(Y)$ measured in units of one million Ren Min Be too. Note that the capital and output values have been adjusted to a 1991 base period to eliminate the impact of price variations. The congestion amount regarding FDH technology using the proposed method as well as the congestion amounts using Cooper et al.s method [6] in BCC technology which are shown by $\left(s_{1}^{c *}, s_{2}^{c *}\right)$ is provided in Table 6 . As can be seen from Table 6, congestion appeared in performance of DMUs 8, 9, 10 , and 15 in $T_{\mathrm{FDH}}$. Besides DMUs 2, 8, 9, 10, 12, 13, and 15 have been recognized to be congested in $T_{\mathrm{BCC}}$. Comparison of these two computational results shows that the DMUs which are congested in $T_{\mathrm{FDH}}$ are among the ones that are congested in $T_{\mathrm{BCC}}$. That is, the set of congested DMUs in $T_{\mathrm{FDH}}$ is a subset of set of congested DMUs in $T_{\mathrm{BCC}}$. It seems reasonable because $T_{\mathrm{FDH}} \subseteq T_{\mathrm{BCC}}$.

\section{Conclusion}

In this paper we proposed a method based on pairwise comparison to evaluate congestion in FDH model. The results of the study have been proved with some lemmas and theorems. Our proposed method is able to identify congestion in performance of DMUs and it can determine the amount of excessive inputs for congested DMUs based on the calculation of certain pairwise differences of inputs and outputs. It also 
TABLE 6: Comparison results of congestion treatment in BCC and FDH technologies in Example 3.

\begin{tabular}{lcccc}
\hline DMU $=$ year & $\begin{array}{c}\left(s_{1}^{c *}, s_{2}^{c *}\right) \\
\text { in FDH }\end{array}$ & $\begin{array}{c}\left(s_{1}^{c *}, s_{2}^{c *}\right) \\
\text { in BCC }\end{array}$ & $\begin{array}{c}\text { Results of the proposed } \\
\text { approach in } T_{\mathrm{FDH}}\end{array}$ & $\begin{array}{c}\text { Results of Cooper et al.'s } \\
\text { approach in } T_{\mathrm{BCC}}[6]\end{array}$ \\
\hline $\mathrm{DMU}_{1}=1981$ & $(0,0)$ & $(0,0)$ & No congestion & No congestion \\
$\mathrm{DMU}_{2}=1982$ & $(0,0)$ & $(0,0.72)$ & Congestion & No congestion \\
$\mathrm{DMU}_{3}=1983$ & $(0,0)$ & $(0,0)$ & No congestion & No congestion \\
$\mathrm{DMU}_{4}=1984$ & $(0,0)$ & $(0,0)$ & No congestion & No congestion \\
$\mathrm{DMU}_{5}=1985$ & $(0,0)$ & $(0,0)$ & No congestion & No congestion \\
$\mathrm{DMU}_{6}=1986$ & $(0,0)$ & $(0,0)$ & No congestion & No congestion \\
$\mathrm{DMU}_{7}=1987$ & $(0,0)$ & $(0,0)$ & No congestion & Congestion \\
$\mathrm{DMU}_{8}=1988$ & $(81.30,0.67)$ & $(65.39,0)$ & Congestion & Congestion \\
$\mathrm{DMU}_{9}=1989$ & $(45.00,0.52)$ & $(45.00,0)$ & Congestion & Congestion \\
$\mathrm{DMU}_{10}=1990$ & $(2.00,0.74)$ & $(43.16,0)$ & Congestion & No congestion \\
$\mathrm{DMU}_{11}=1991$ & $(0,0)$ & $(0,0)$ & No congestion & Congestion \\
$\mathrm{DMU}_{12}=1992$ & $(0,0)$ & $(30.72,0)$ & No congestion & Congestion \\
$\mathrm{DMU}_{13}=1993$ & $(0,0)$ & $(1.79,0)$ & No congestion & No congestion \\
$\mathrm{DMU}_{14}=1994$ & $(0,0)$ & $(0,0)$ & No congestion & Congestion \\
$\mathrm{DMU}_{15}=1995$ & $(7.70,4.33)$ & $(0,3.98)$ & Congestion & No congestion \\
$\mathrm{DMU}_{16}=1996$ & $(0,0)$ & $(0,0)$ & No congestion & No congestion \\
$\mathrm{DMU}_{17}=1997$ & $(0,0)$ & $(0,0)$ & No congestion &
\end{tabular}

is capable of detecting the losses amounts of output due to congestion. One of the advantages of this method is that in all stages there is no need to solve any mathematical programming problems and so a polynomial time algorithm to identify congestion in FDH model is provided. Hence, it is superior from a computational point of view. The numerical examples demonstrated the compatibility of the proposed approach and so can be developed in performance analysis and large practical projects.

Because of having low complexity of computation, this method can be developed for imprecise data for further research.

\section{Conflict of Interests}

The authors declare that there is no conflict of interests regarding the publication of this paper.

\section{References}

[1] W. W. Cooper, L. Seiford, and K. Tone, Introduction to Data Envelopment Analysis and its Uses: With DEA-Solver Software and References, Springer, New York, NY, USA, 2005.

[2] R. Färe and S. Grosskopf, "Measuring congestion in production," Zeitschrift für Nationalökonomie, vol. 43, no. 3, pp. 257271, 1983.

[3] R. Färe, S. Grosskopf, and C. A. K. Lovell, The Measurement of Efficiency of Production, Kluwer-Nijhoff Publishing, Boston, Mass, USA, 1985.

[4] W. W. Cooper, R. G. Thompson, and R. M. Thrall, "Introduction: extensions and new developments in DEA," Annals of Operations Research, vol. 66, pp. 3-45, 1996.

[5] W. W. Cooper, H. Deng, B. Gu, S. Li, and R. M. Thrall, "Using DEA to improve the management of congestion in Chinese industries (1981-1997)," Socio-Economic Planning Sciences, vol. 35, no. 4, pp. 227-242, 2001.

[6] W. W. Cooper, L. M. Seiford, and J. Zhu, "A unified additive model approach for evaluating inefficiency and congestion with associated measures in DEA," Socio-Economic Planning Sciences, vol. 34, no. 1, pp. 1-25, 2000.

[7] K. Tone and B. K. Sahoo, "Degree of scale economies and congestion: a unified DEA approach," European Journal of Operational Research, vol. 158, no. 3, pp. 755-772, 2004.

[8] Q. L. Wei and H. Yan, "Congestion and returns to scale in data envelopment analysis," European Journal of Operational Research, vol. 153, no. 3, pp. 641-660, 2004.

[9] G. R. Jahanshahloo and M. Khodabakhshi, "Suitable comb ination of inputs for improving outputs in DEA with determining input congestion :considering textile indus try of China," Applied Mathematics and Computation, vol. 151, no. 1, pp. 263273, 2004.

[10] G. R. Jahanshahloo and M. Khodabakhshi, "Determining assurance interval for non-Archimedean element in the improving outputs model in DEA," Applied Mathematics and Computation, vol. 151, no. 2, pp. 501-506, 2004.

[11] M. Khodabakhshi, "A one-model approach based on relaxed combinations of inputs for evaluating input congestion in DEA," Journal of Computational and Applied Mathematics, vol. 230, no. 2, pp. 443-450, 2009.

[12] M. Khodabakhshi, "Chance constrained additive input relaxation model in stochastic data envelopment analysis," International Journal of Information and Systems Sciences, vol. 6, no. 1, pp. 99-112, 2010.

[13] M. Khodabakhshi, "An output oriented super-efficiency measure in stochastic data envelopment analysis: considering Iranian electricity distribution companies," Computers and Industrial Engineering, vol. 58, no. 4, pp. 663-671, 2010.

[14] M. Asgharian, M. Khodabakhshi, and L. Neralic, "Congestion in stochastic data envelopment analysis: an input relaxation 
approach," International Journal of Statistics and Management System, vol. 5, no. 1, pp. 84-106, 2010.

[15] G. R. Jahanshahloo, M. Khodabakhshi, F. H. Lotfi, and M. R. Goudarzi, "Computation of congestion in DEA models with productions trade-offs and weight restrictions," Applied Mathematical Sciences, vol. 5, no. 13-16, pp. 663-676, 2011.

[16] M. Khodabakhshi, R. M. Goudarzi, M. Y. Maryaki, and M. Hajiani, "A one-model approach for computation of congestion with productions trade-offs and weight restrictions," International Journal of Applied Operational Research, vol. 3, no. 4, pp. 69-80, 2013.

[17] T. Sueyoshi and K. Sekitani, "DEA congestion and returns to scale under an occurrence of multiple optimal projections," European Journal of Operational Research, vol. 194, no. 2, pp. 592-607, 2009.

[18] M. Khodabakhshi, F. Hosseinzadeh Lotfi, and K. Aryavash, "Review of input congestion estimating methods in DEA," Journal of Applied Mathematics, vol. 2014, Article ID 963791, 9 pages, 2014.

[19] D. Deprins, L. Simar, and H. Tulkens, "Measuring laborefficiency in post offices," in The Performance of Public Enterprises, M. Marchand, P. Pestieau, and H. Tulkens, Eds., pp. 243267, Elsevier Science, Amsterdam, The Netherlands, 1984.

[20] K. Kerstens and P. V. Eeckaut, "Estimating returns to scale using non-parametric deterministic technologies: a new method based on goodness-of-fit," European Journal of Operational Research, vol. 113, no. 1, pp. 206-214, 1999.

[21] V. V. Podinovski, "On the linearisation of reference technologies for testing returns to scale in FDH models," European Journal of Operational Research, vol. 152, no. 3, pp. 800-802, 2004.

[22] M. Soleimani-damaneh, G. R. Jahanshahloo, and M. Reshadi, "On the estimation of returns-to-scale in FDH models," European Journal of Operational Research, vol. 174, no. 2, pp. 10551059, 2006.

[23] M. Soleimani-damaneh and M. Reshadi, "A polynomial-time algorithm to estimate returns to scale in FDH models," Computers and Operations Research, vol. 34, no. 7, pp. 2168-2176, 2007.

[24] M. Soleimani-Damaneh and A. Mostafaee, "Stability of returns to scale in FDH models," European Journal of Operational Research, vol. 196, pp. 1223-1228, 2009.

[25] W. W. Cooper, H. Deng, Z. M. Huang, and S. X. Li, "A onemodel approach to congestion in data envelopment analysis," Socio-Economic Planning Sciences, vol. 36, no. 4, pp. 231-238, 2002.

[26] H. Tulkens, "On FDH efficiency analysis: some methodological issues and applications to retail banking, courts, and urban transit," Journal of Productivity Analysis, vol. 4, no. 1-2, pp. 183210, 1993. 


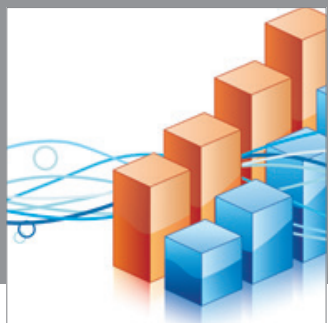

Advances in

Operations Research

mansans

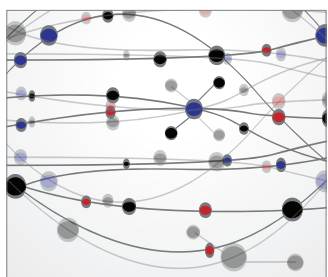

The Scientific World Journal
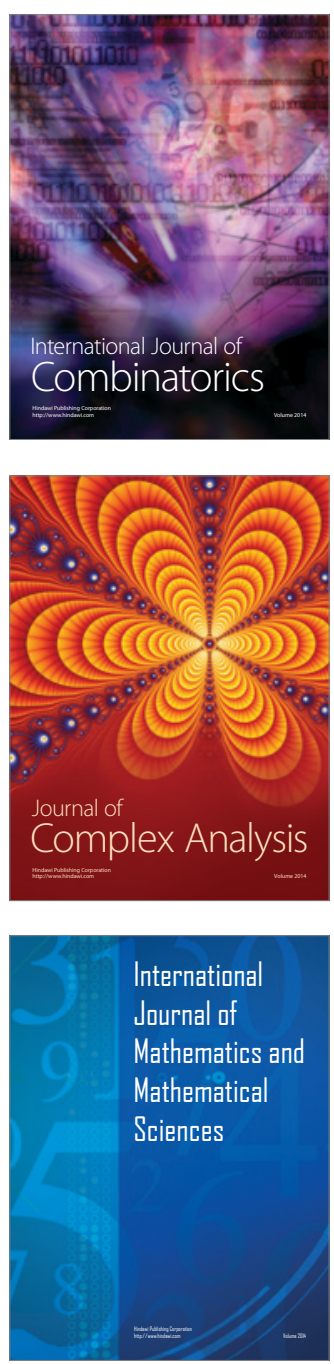
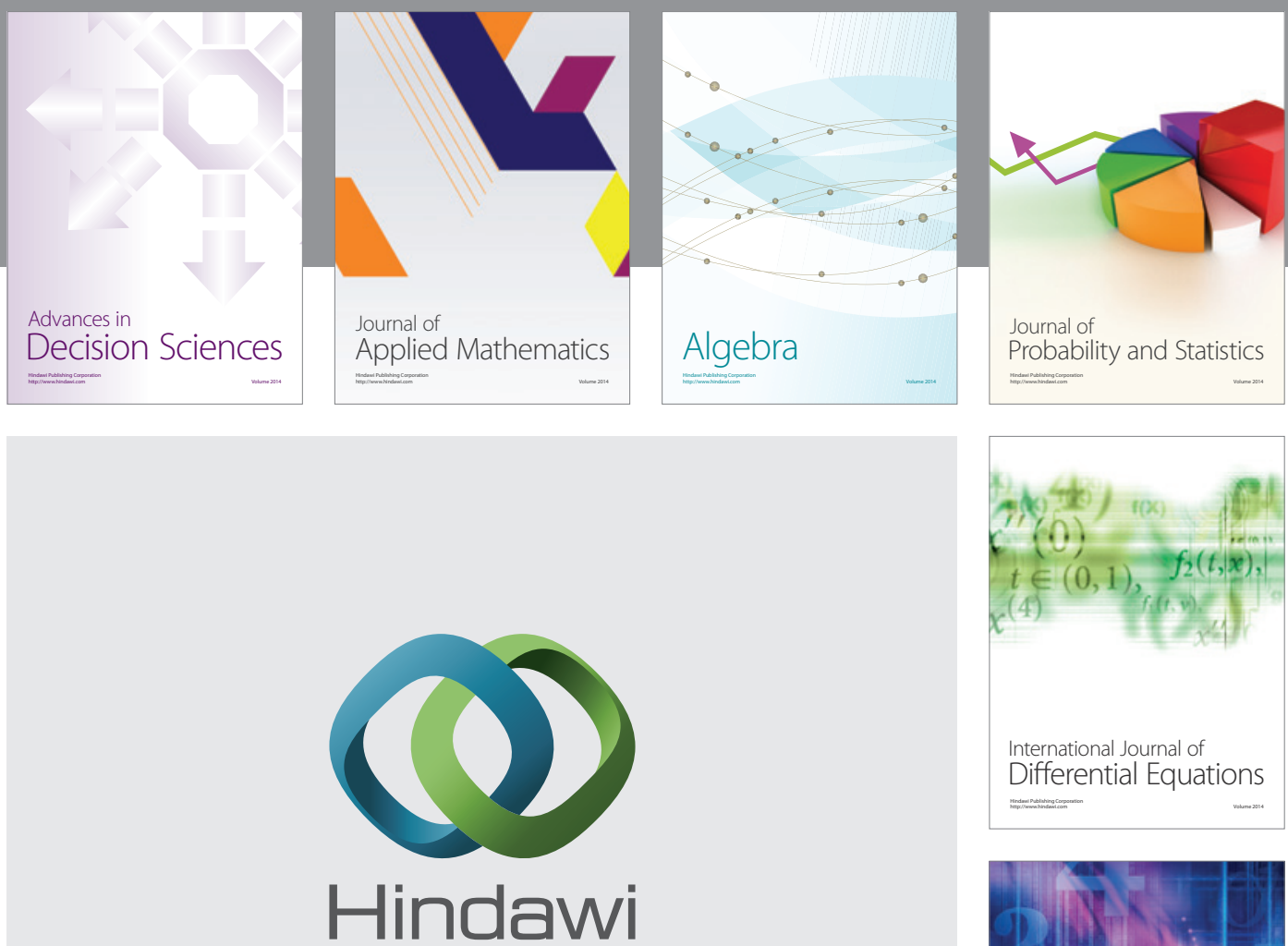

Submit your manuscripts at http://www.hindawi.com
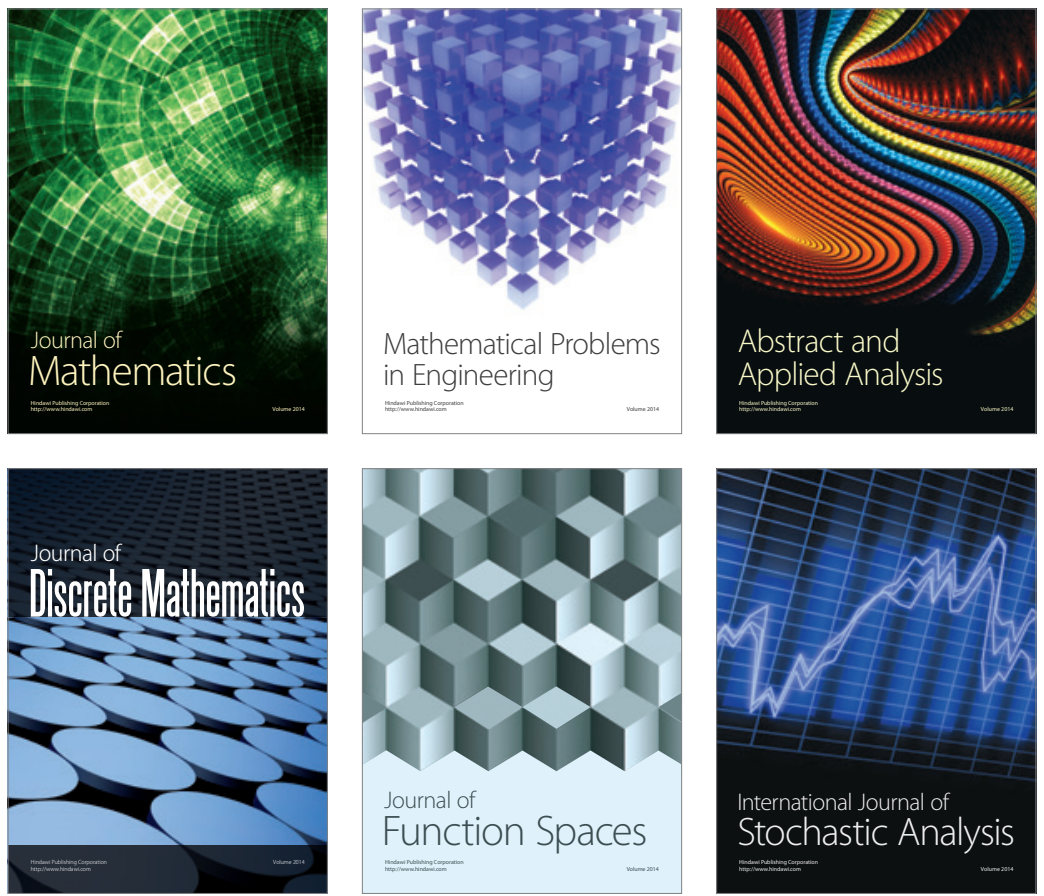

Journal of

Function Spaces

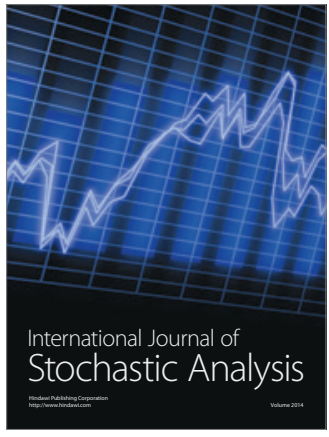

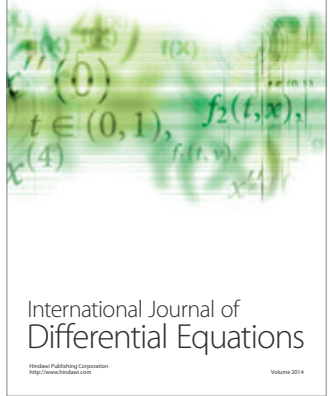
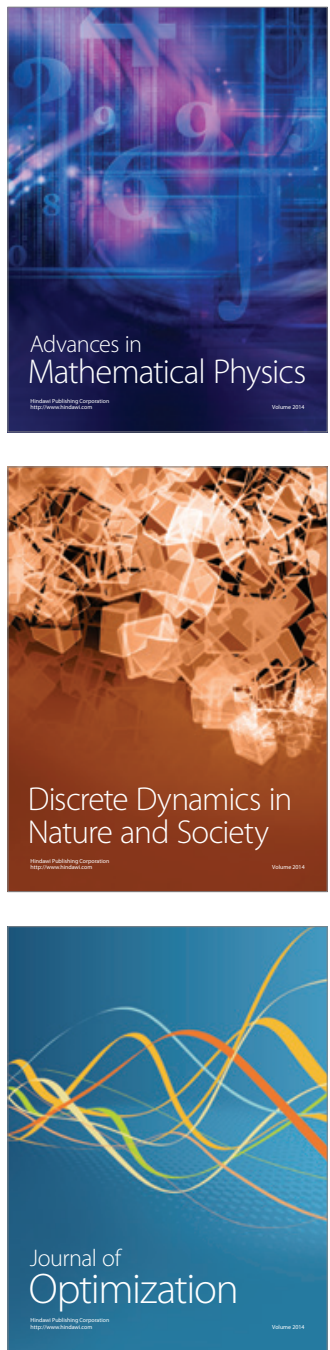